\title{
Sosialisasi pembuatan paving block cari limbah plastik berbasis pemberdayaan masyarakat di Kota Makassar
}

\author{
Syamfitriani Asnur ${ }^{1}$, Arman Setiawan ${ }^{2}$ \\ ${ }_{1,2}^{1}$ Fa kultas Teknik, Universitas Bosowa
}

\begin{abstract}
The Community Partnership Program(PKM) are people who are members of the Pabbata Ummi TPA Antang Foundation, which consists of Youth and Fathers groups and groups of mothers in RT 02 and 03 Tamangapa Village, Manggala District, Makassar City. The problem is: (1) constraints of knowledgeand skills in processing plastic waste, especially for making paving blocks, (2) preparation of paving block manufacturing businesses. The external target is the use of plastic waste and technology that can turn it into a long-lived product so that it does not return to wa ste in a short timeand has a high selling value so that it can improve the standard of living of citizens. The method used is: lectures, demonstrations, discussions, questions and answers, a nd coun terpart part ners. The results achieved are (1) partners have knowledge and skills in processing plastic wa ste, especially paving blocks, (2) partners have preparation to start a bu siness making paving blocks.
\end{abstract}

Key words: paving block, pla stic wa ste, training, Tamangapa

\section{PENDAHULUAN}

Makassar dengan jumlah penduduk lokal mencapai sekitar 1,3 juta jiwa, menghasilkan sekitar $3.800 \mathrm{~m}^{3}$ atau setara dengan 300 ton sampah perkotaan setiap harinya. Padahal kapasitas maksimum dari TPA Tamangapa hanya sekitar $2.800 \mathrm{~m}^{3}$ sampah perkotaan setiap harinya. Diperlukan tambahan lahan TPA untuk pembuangan $1000 \mathrm{~m}^{3}$ sisa sampah. Oleh sebab itu, dibutuhkan rencana dan pengelolaan sampah padat perkotaan yang memadai untuk mengatasi masalah ini. Sekitar $87 \%$ sampah di Makassar merupakan sampah organik dan sekitar $13 \%$ adalah sampah anorganik, seperti plastik dan kertas. Plastik sendiri merupakan suatu jenis bahan yang tidak dapat terurai dalam waktu yang singkat. Sampah plastik membutuhkan waktu 200 sampai 1000 tahun untuk dapat terurai. Menurut Peraturan Pemerintah Nomor 81 Tahun 2012, pengelolaan sampah adalah kegiatan yang sistematis, menyeluruh dan berkesinambungan yang meliputi pengurangan dan penanganan sampah. Pengurangan sampah terdiri dari 3R yaitu mereduksi timbulan (reduce), pemanfaatan kembali (reuse) dan daur ulang (recycle).Sedangkan penanganan sampah meliputi pemilahan atau pewadahan, pengumpulan, pengangkutan, pengolahan dan pemrosesan akhir.
Pemanfaatan sampah plastik telah dilakukan, antara lain dengan membuat kerajinan, aspal, dan produk lainnya. Tetapi penggunaan plastik sebag ai produk kerajinan belum menyelesaikan masalah karena pada satu saat produk tersebut akan rusak dan kembali lagi menjadi sampah. Diperlukan suatu teknologi yang dapat mengubah sampah plastik menjadi produk yang berumur lama sehingga tidak kembali menjadi sampah dalam waktu yang singkat. Pembuatan produk paving block dari plastik merupakan salah satu alternatif pemanfaatan limbah plastik dalam jangka waktu yang lama, dalam rangka meningkatkan efisiensi pemanfaatan dan mengurangi pembebanan lingkungan terhadap limbah plastik serta menghasilkan produk-produk inovatif sebagai bahan bangunan. Selain itu keunggulan lain dari paving block berbahan limbah plastik adalah lebih kuat dibandingkan paving biasa.

Tujuan dari program pengabdian masyarakat ini adalah (1) sebagai alternatif pemanfaatan limbah plastik yang banyak terdapat di TPA Antang, khususnya plastik jenis PET dan (2) mengurangi sampah plastik. Sedangkan manfaatnya adalah (1) memberi pengetahuan tentang pemanfaatan limbah plastik menjadi barang yang bernilai jual lebih tinggi dibandingkan dijual dalam bentuk mentah, 
(2) menambah pengetahuan dan ketrampilan masyarakat akan pembuatan paving block dari limbah plastik dan (3) salah satu alternatif pilihan peluang usaha untuk menambah sumber pendapatan sehingga penghasilan keluarga menjadi bertambah.

\section{METODE PELAKSANAAN}

a. Agar mitra memiliki pengetahuan dan keterampilan pengolahan limbah plastik khususnya untuk pembuatan paving block, maka metode yang digunakan adalah ceramah, demonstrasi, diskusi, tanya jawab dan pendampingan mitra.

b. Agar mitra memiliki persiapan usaha pembuatan paving block, maka metode yang digunakan adalah demonstrasi,diskusi, tanya jawab dan pendampingan mitra.

\section{PELAKSANAAN DAN HASIL KEGIATAN}

\section{A. Pembuatan Paving Block}

Pelaksanaan program pengabdian masyarakat ini dimulai pada awal bulan Mei 2019. Program ini ditujukan kepada masyarakat yang tergabung dalam binaan Yayasan Pabbata Ummi yang terdiri dari kelompok Pemuda dan Bapak-Bapak serta kelompok Ibu-Ibu di RT 02 dan 03 Kelurahan Tamangapa Kecamatan Manggala Kota Makassar. Pembuatan paving block dengan memanfaatkan limbah plastik non biodegradable yang didapatkan dari warga di sekitar TPA Antang kelurahan Tamangapa Kecamatan Manggala, yang sebagian besar berprofesi sebagai pengepul sampah.
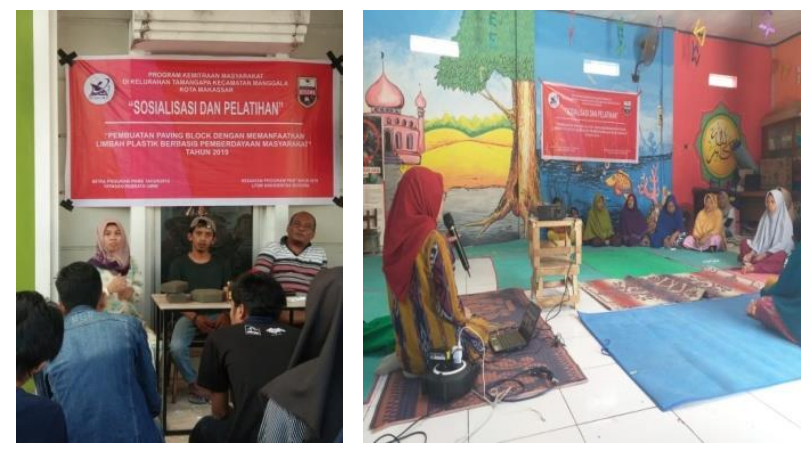

Gambar 1. Sosialisasi pemanfaatan sampah plastik

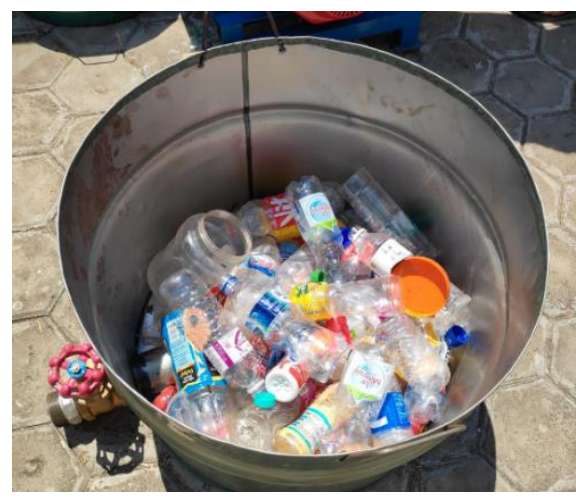

Gambar 2. Sampah plastik jenis PET

Metode dalam pembuatan paving block adalah sebagai berikut:

1. Mengumpulkan sampah plastik dari keseluruhan sampah anorganik.

2. Memilah sampah plastik dari sampah plastik yang bersifat biodegradable.

3. Memotong plastik menjadi bagian kecil sehingga lebih cepat meleleh.

4. Mencampur rata semen dan pasir dengan perbandingan 1:6.

5. Komposisi Plastik dan campuran pasir-semen ini dibuat dengan perbandingan 45\%:55\%, dan oli bekas secukupnya.

6. Memanaskan oli bekas dan memasak plastik diatas suhu $300^{\circ} \mathrm{C}$, sampai plastik meleleh.

7. Memasukkan campuran agregat pasir-semen ke dalam adonan plastik, sedikit demi sedikit dan mengaduknya sampai tercampur rata.

8. Mencetak campuran.

9. Mengeluarkan paving dari cetakan dengan merendamnya dalam air.

10. Mengeringkan campuran dan uji paving block.

Pembuatan paving block ini dimulai dengan memanaskan oli bekas, setelah mendidih kemudian plastik dimasukkan sedikit demi sedikit sampai plastik meleleh. Proses memasak plastik ini diatas suhu $300^{\circ} \mathrm{C}$. Setelah plastik meleleh atau mencair, lalu agregat pasir yang sebelumnya telah dicampur semen dengan perbandingan 1:6, dimasukkan sedikit demi sedikit sambil diaduk terus sampai adonan tercampur rata.setelah adonan tercampur dengan rata, maka adonan siap dicetak dalam cetakan paving sesuai model yang diinginkan dan 
ditekan selama 2 menit. Proses mencetak ini harus dilakukan dengan cepat karena adonan ini cepat mengering disebabkan campuran semen yang terdapat didalamnya. Setelah mengeras paving dikeluarkan dari cetakan dengan cara merendam dalam air selama beberapa menit. Setelah paving kering maka siap digunakan. Komposisi paving ini adalah $45 \%$ plastik dan $55 \%$ campuran pasirsemen. Dengan komposisi ini, untuk $2 \mathrm{~kg}$ plastik dapat menghasilkan 2 buah paving block berbentuk segiempat dengan ketebalan $5,5 \mathrm{~cm}$.
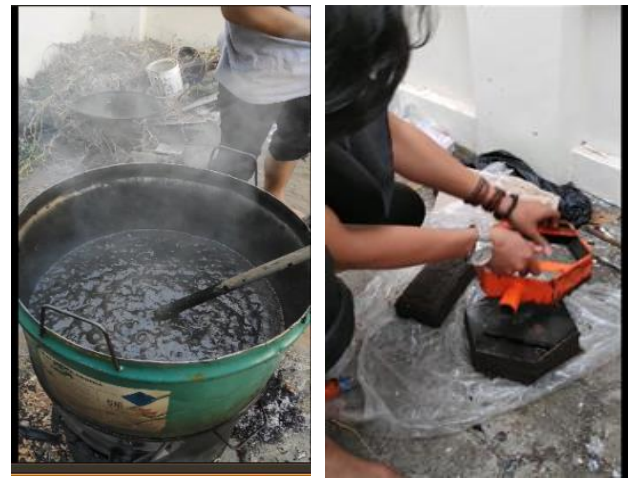

Gambar 3. Demo pembuatan paving block dari limbah plastik

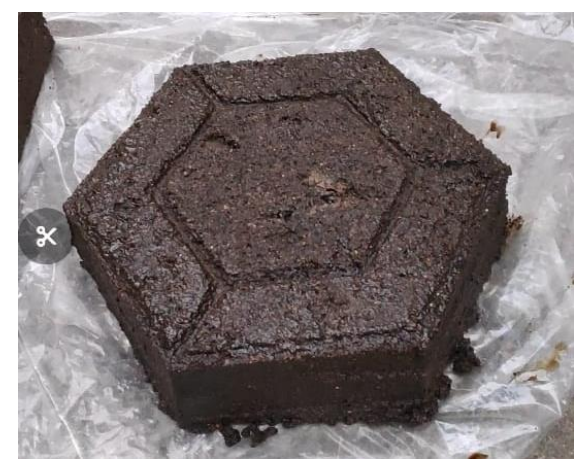

Gambar 4. Hasil cetakan paving model segiempat

\section{B. Peralatan}

Dalam pelaksanaan kegiatan ini, dibutuhkan perangkat teknologi yang digunakan antara lain:

1. Perakitan mesin pencacah/ pemotong plastik,

2. Panci untuk melelehkan plastic,

3. Spatula/ pengaduk,

4. Kompor pemanasan,

5. Alat cetakan paving,

6. Alat press.
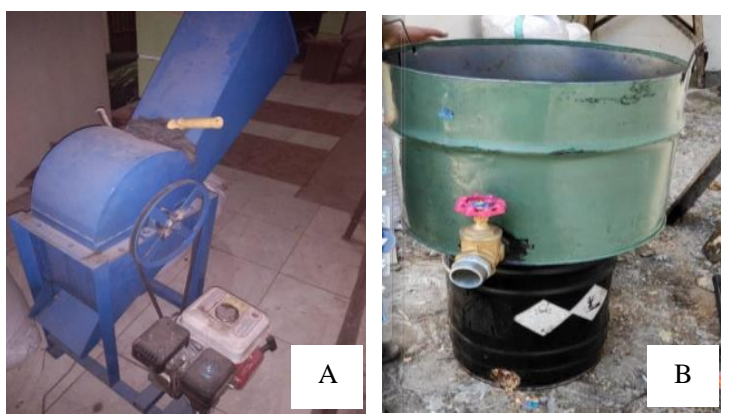

Gambar 5. A) Mesin pencacah plastic kapasitas $20 \mathrm{~kg} / \mathrm{jam}$, dan B) Model kompor dan panic pemanasan
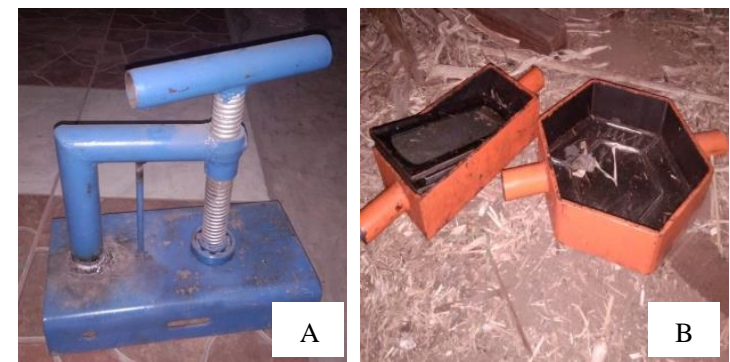

Gambar 6. A) Alat press dan B) Cetakan paving model segiempat dan segienam

\section{KESIMPULAN}

Hasil pelaksanaan kemitraan masyarakat dapat ditarik kesimpulan:

a. Mitra memiliki pengetahuan dan keterampilan dalam pengolahan limbah plastik khususnya menjadi paving block.

b. Mitra memiliki persiapan awal usaha berupa pengetahuan dan keterampilan menggunakan alat serta memiliki peralatan.

c. Usaha Paving blok ini bisa menjadi peluang usaha bagi masyarakat sekitar TPA Antang Kelurahan Tamangapa, sehingga bisa menambah penghasilan keluarga.

d. Pembuatan Paving blok dari limbah plastik ini mendukung program pemerintah dalam mengurangi sampah khususnya plastik.

\section{UCAPAN TERIMA KASIH}

Ucapan terimakasih disampaikan kepada Direktorat Jendral Pendidikan Tinggi yang telah memberikan hibah. Selanjutnya ucapan terima kasih disampaikan pula kepada Rektor Universitas Bosowa atas arahan dan pembinaanya selama proses kegiatan Pengabdian Masyarakat ber- 
langsung. Demikian pula ucapan terimakasih disampaikan kepada Ketua Lembaga Pengabdian Kepada Masyarakat Universitas Bosowa dan Yayasan Pabbata Ummi TPA Tamangapa, yang telah memberi fasilitas, melakukan monitoring, dan mengevaluasi kegiatan PKM hingga selesai.

\section{DAFTAR PUSTAKA}

Peraturan Pemerintah No. 81 Tahun 2012. Tentang Pengelolaan Sampah Rumah Tangga dan Sampah Sejenis Rumah Tangga. 